\title{
A Patient with Leonine Facies and Occult Lung Disease
}

\author{
S.M.H. Kannenberg ${ }^{a}$ C.F.N. Koegelenberg ${ }^{b}$ H.F. Jordaan ${ }^{a}$ C.T. Bolliger ${ }^{b}$ \\ Divisions of a Dermatology and ${ }^{\mathrm{b}}$ Pulmonology, Department of Medicine, University of Stellenbosch and \\ Tygerberg Academic Hospital, Cape Town, South Africa
}

A 70-year-old male patient presented with a 2-week history of a skin eruption involving the face, neck, axillae, groin, palms, and dorsa of the hands. He had no systemic complaints and no significant past medical or surgical history. He was a smoker (30 pack years), and had no specific occupational exposure.

On examination he was found to have leonine facies (fig. 1), with coarse facial features and grey velvety plaques on pressure areas of the face. He was also noted to have velvety hyperpigmentation in the neck (fig. 2), axillae and the groin. Furthermore, the dorsa of the hands had brown thickened skin with a pebbly appearance (fig. 3) and the palms showed rugose thickening with more pronounced skin markings (fig. 4). His general and systemic clinical examination was otherwise unremarkable.

What are the clinical diagnoses and, more importantly, which pulmonary affliction is associated with these conditions?

\section{KARGER}

Fax +41613061234 E-Mail karger@karger.ch www.karger.com
Dr. Coenraad F.N. Koegelenberg

Division of Pulmonology, Department of Medicine

University of Stellenbosch

POB 19063, Tygerberg, Cape Town 7505 (South Africa)

Tel. +27 21938 9423, Fax +27 21933 3591, E-Mail coeniefn@sun.ac.za 


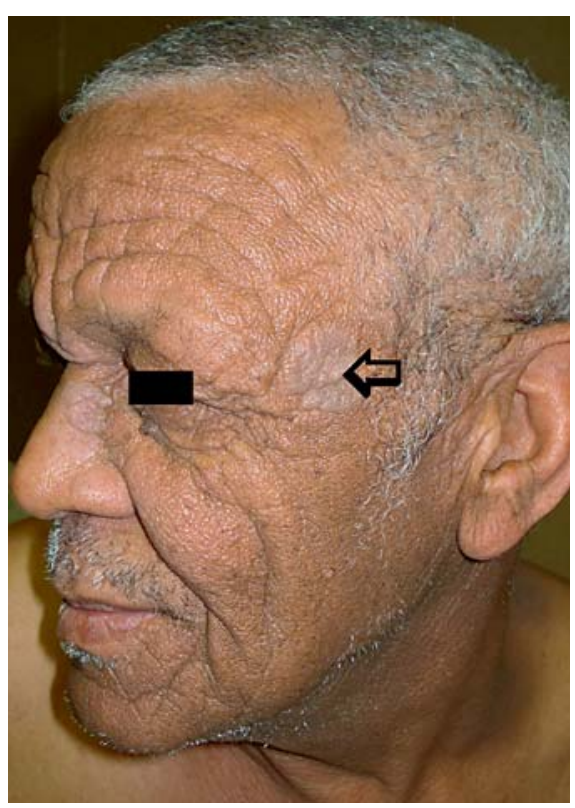

Fig. 1. The patient presented with coarse facial features and greyish plaques on pressure areas (arrow and lateral aspect of the nose).

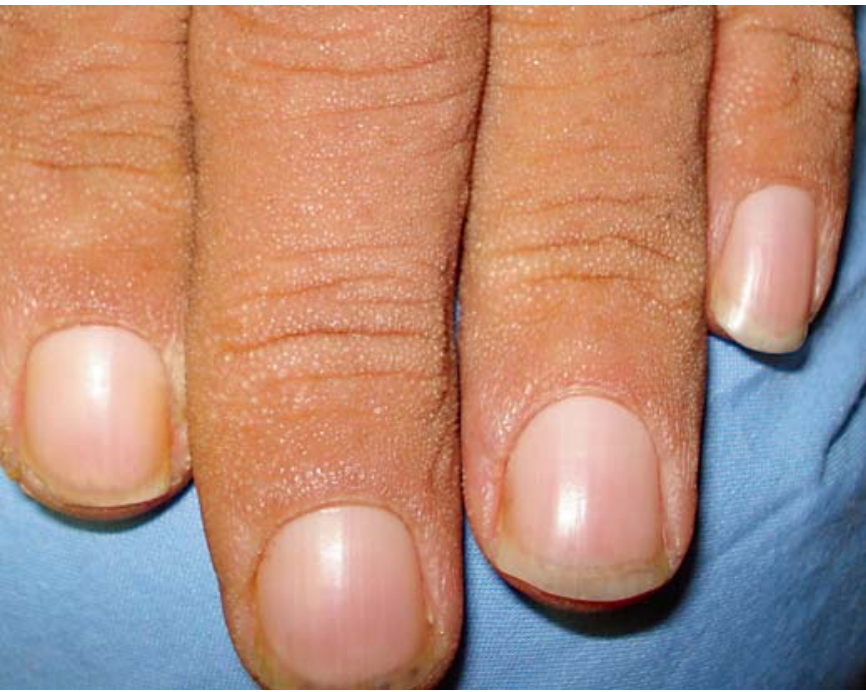

Fig. 3. The dorsa of the hands revealed brown thickened skin with a pebbly appearance.

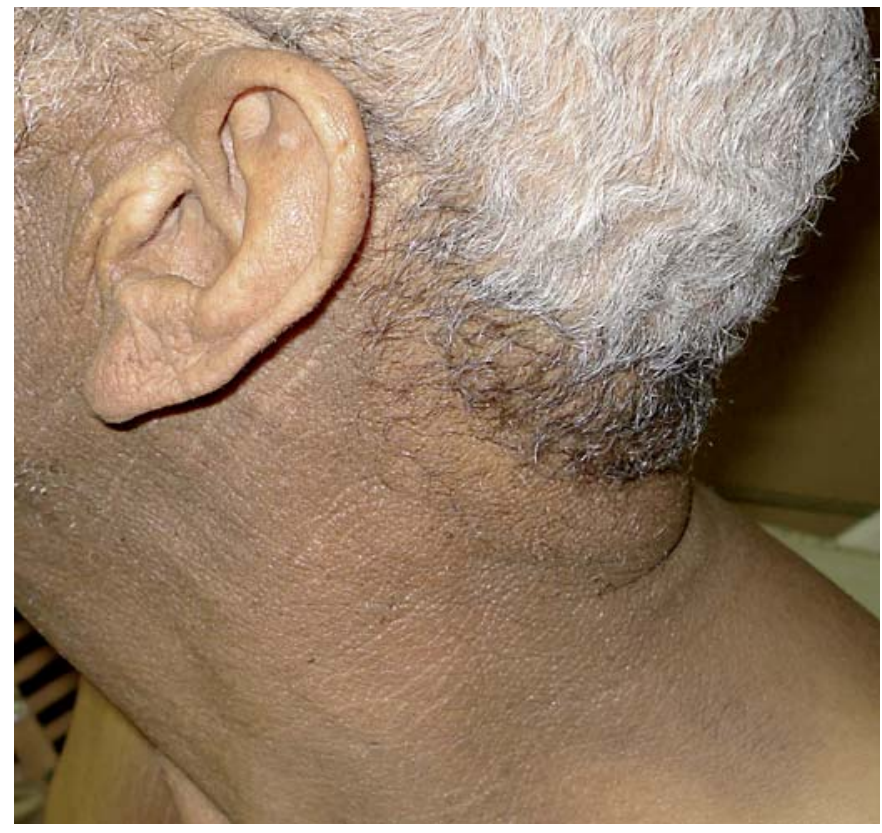

Fig. 2. Extensive velvety hyperpigmentation of the neck was present.

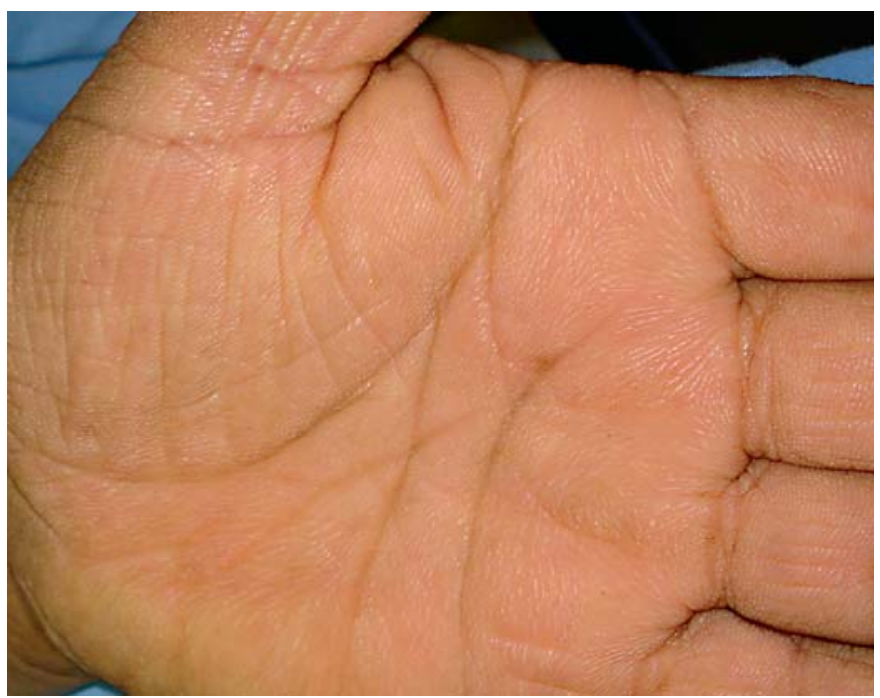

Fig. 4. This close-up view of the palm of the left hand demonstrates the rugose thickening and more pronounced skin markings. 


\section{Diagnoses: Paraneoplastic Acanthosis Nigricans and Pachydermatoglyphy Secondary to Adenocarcinoma of the Lung}

The clinical diagnoses of paraneoplastic acanthosis nigricans (PNAN) and pachydermatoglyphy (PDG) were made. Histological examination of a skin biopsy showed acanthosis, hyperorthokeratosis and delicate elongated papillomatosis, in keeping with the diagnosis of acanthosis nigricans (AN).

A chest radiograph (fig. 5) revealed an ill-defined mass lesion in the right upper zone, and a subsequent CT scan (fig. 6a) confirmed the presence of a spiculated mass in the right upper lobe measuring $24 \times 27 \times 23 \mathrm{~mm}$, as well as pathological mediastinal lymphadenopathy (fig. 6b), with the retrocaval, subcarinal and aortopulmonary lymph nodes measuring $>1 \mathrm{~cm}$ in their respective short axes. This scan was also highly suggestive of a right adrenal gland metastasis. A PET-CT scan demonstrated avid uptake in the lesion, as well as all the above-mentioned mediastinal lymph nodes. The right adrenal gland was also found to have marked increased uptake of fluorodeoxyglucose. The patient underwent a flexible bronchoscopy with transbronchial lymph node aspirations of mediastinal lymph nodes, which confirmed the diagnosis of adenocarcinoma. No endobronchial lesions were seen during the procedure.

Leonine facies or leontiasis is characterized by thickening and increased furrowing of the face due to cutaneous infiltrations, leading to a lion-like appearance [1]. The prototypic disease causing this phenomenon is lepromatous leprosy, but various diseases affecting the different layers of the skin may give rise to this appearance. The involvement may be dermal (e.g. amyloidosis and sarcoidosis), epidermal (e.g. AN and chronic actinic dermatitis), or a combination of dermal and epidermal (e.g. hypereosinophilic syndrome and cutaneous T-cell lymphoma) [1]. Other conditions causing a leonine facies include pachydermoperiostosis, lipoid proteinosis, scleromyxedema, multiple keratoacanthoma syndrome, Kaposi's sarcoma and multicentric reticulohistiocytosis.

The first cases of AN were described in 1890 by Janovsky [2] and Politzer [3]. AN may be defined as a mucocutaneous dermatosis with a predilection for the skin folds, nape and sides of the neck, most often in a symmetrical distribution [4]. Clinically hyperpigmented plaques with variable degrees of epidermal hyperplasia are observed, giving rise to a velvety texture [4]. Eight subtypes of AN are recognised: (1) benign, (2) obesity-associated, (3) syn-

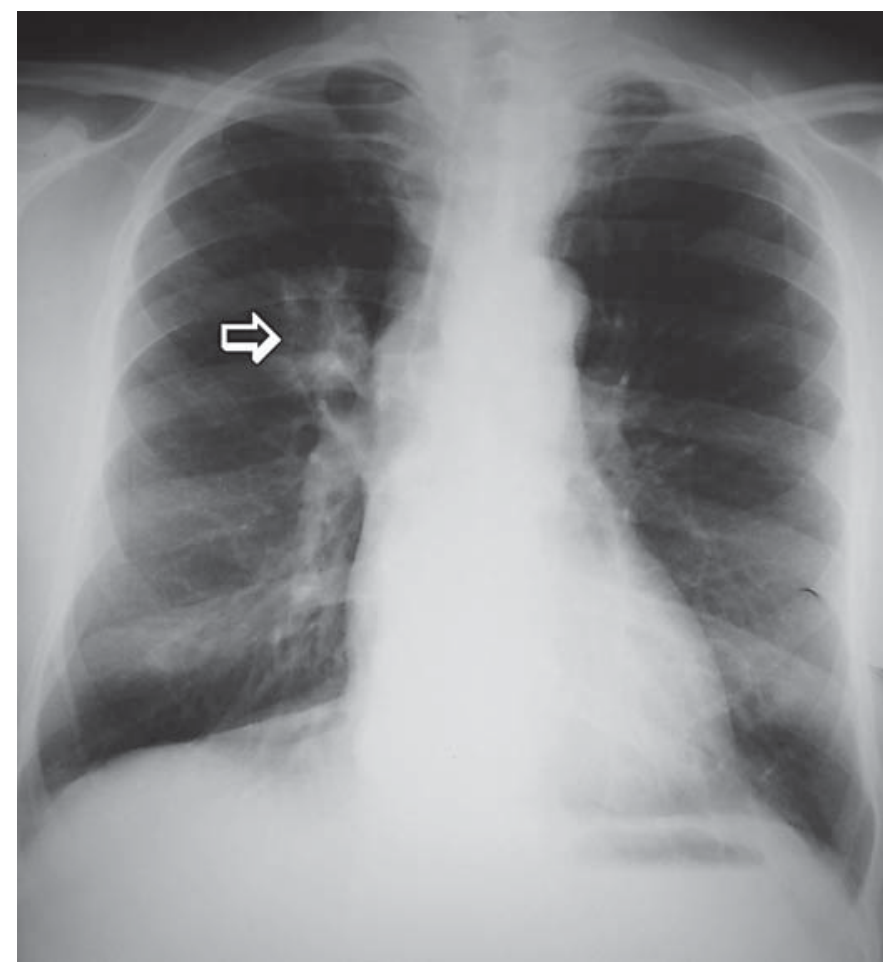

Fig. 5. The chest radiograph revealed a poorly circumscribed mass in the right upper zone (arrow).

dromic, (4) paraneoplastic, (5) acral, (6) unilateral, (7) medication-induced and (8) mixed type [4].

PNAN is rare with approximately a thousand cases reported in the world literature [5]. The commonest associated malignancy is adenocarcinoma, most often of gastric origin [6], but reports of lung squamous cell carcinomas are also documented [7-9]. PNAN precedes the diagnosis of the malignancy in more than half of cases, but it may appear simultaneously or follow the diagnosis in 13 and 29\%, respectively [10]. PNAN is characterized by an abrupt onset, rapid progression and widespread distribution involving unusual locations [11-14]. Mucosal involvement is found in $35 \%$ of cases where it has a more papillated appearance $[12,13]$. Any mucosal surface may be affected, even the larynx [11]. PNAN may be associated with extensive wart-like growths ('florid cutaneous papillomatosis') [14] and PDG [11].

Synonyms for PDG include 'AN of the palms' [11] and 'tripe palms' [15], as it resembles the edible lining of bo- 

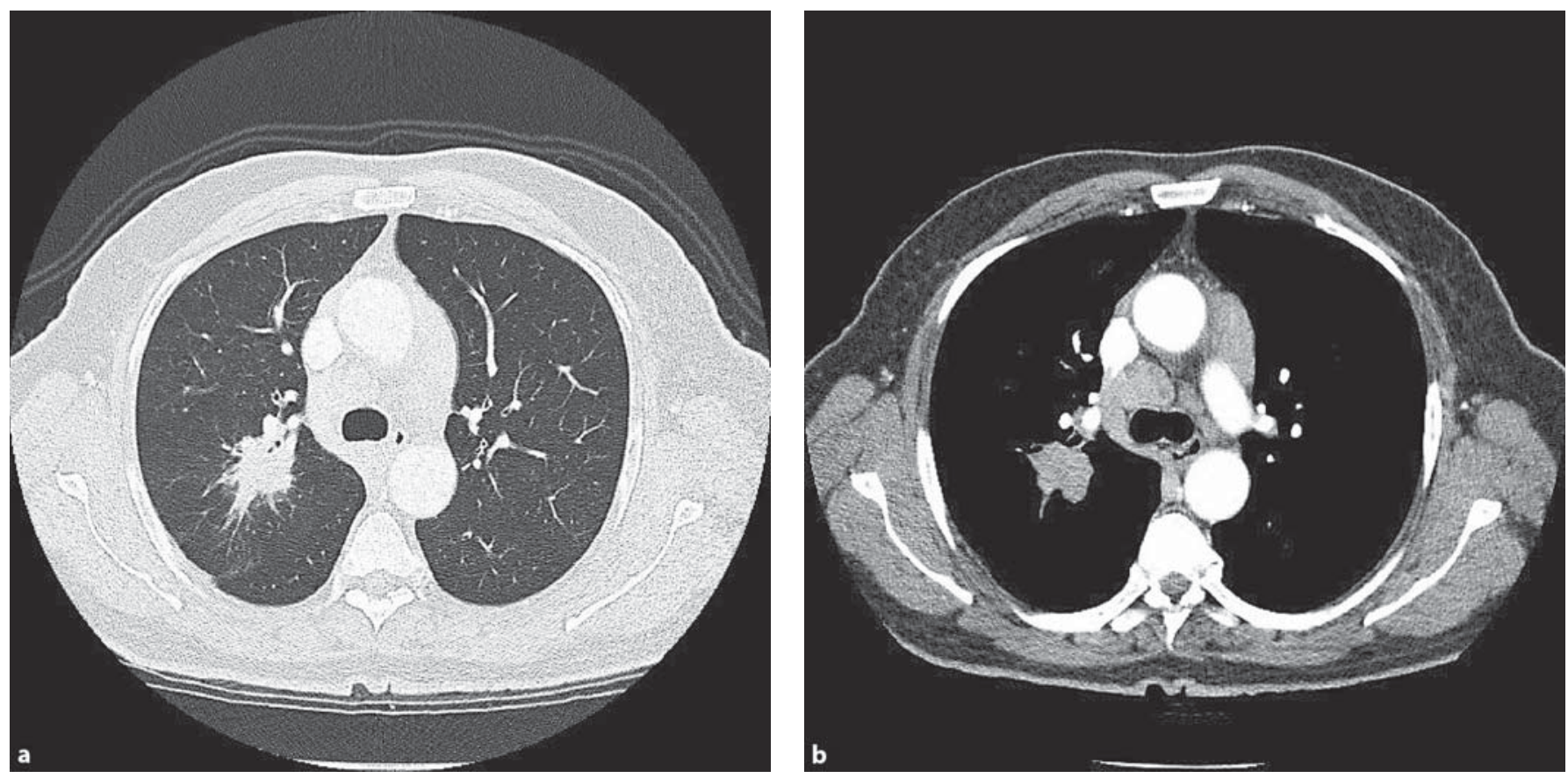

Fig. 6. a A right upper lobe spiculated mass was demonstrated on parenchymal views of the CT scan. b The mediastinal view showed marked mediastinal lymphadenopathy, with large retrocaval, subcarinal (not visible on this slice) and aortopulmonary lymph nodes. A right adrenal metastasis was also found (not shown).

vine foregut. PDG is exceedingly rare with less than 100 cases reported [16]. It is characterized by a yellowish rugose hypertrophy of the palms and sometimes the soles, leading to an exaggeration of the skin lines $[15,16]$. Extensive epidermal hyperkeratosis may cause distortion of the dermatoglyphics [17]. PDG is usually associated with PNAN, but may occur in isolation [16]. It is associated with neoplasms in more than $90 \%$ of cases [16] and, in the majority, pulmonary and gastric carcinomas are the underlying malignancies found. In PDG without AN, especially when clubbing is present, bronchogenic carcinomas account for more than half of cases [16]. Non-malignancy-associated PDG have also been reported in patients with bullous pemphigoid [18], psoriasis [15] and exfoliative dermatitis [15].

PNAN and PDG are considered to be separate entities, existing on a continuum, with similar proposed etiologies [4], namely an increased production of transforming growth factor $\alpha$ by the tumor which upregulates the amount of epidermal growth factor receptors, leading to a relative overproduction of growth factors, resulting in an increased proliferation of keratinocytes [19].

The treatment of these conditions is mainly aimed at the treatment of the underlying malignancy [4]. A whole array of palliative therapies have been attempted, including keratolytics, topical corticosteroids, systemic retinoids and phototherapy [20], but most have been minimally or not effective at all [21-23]. The prognosis is generally poor with a median survival of less than 2 years, as more than half of cases have metastases at the time of diagnosis $[6,24,25]$.

Our patient was referred for palliative chemotherapy, but declined treatment for his lung cancer. Four months after the initial presentation he was still paucisymptomatic with regard to his pulmonary neoplasm, but verrucous lesions had developed on the dorsa of his hands, implying progression of his dermatosis.

This case serves to highlight the importance of paraneoplastic cutaneous syndromes and the fact that these syndromes often precede the clinical presentation of systemic malignancies by many months.

\section{Key Words}

Adenocarcinoma $\cdot$ Lung cancer $\cdot$ Malignant acanthosis nigricans $\cdot$ Pachydermatoglyphy 


\section{References}

1 Rapini RP: Clinical and pathologic differential diagnosis; in Bolognia JL, Jorizzo JL, Rapini RP (eds): Dermatology, ed 2. Amsterdam, Elsevier, 2008, p 4.

2 Janowsky V: Acanthosis nigricans; in Unna PG, Morris M, Besnier E, et al (eds): International Atlas of Rare Skin Diseases, Part 1. London, Lewis, 1890, p 1.

3 Politzer S: Acanthosis nigricans; in Unna PG, Morris M, Besnier E, et al. (eds): International Atlas of Rare Skin Diseases, Part 1. London, Lewis, 1890, p 6.

4 Schwartz RA: Acanthosis nigricans. J Am Acad Dermatol 1994;31:1-19.

$\checkmark 5$ Sedano HO, Gorlin RJ: Acanthosis nigricans. Oral Surg Oral Med Oral Pathol 1987; 63:462-467.

$\checkmark 6$ Curth HO: Cancer associated with acanthosis nigricans. Arch Surg 1943;47:517-552.

$\checkmark 7$ Wedge CC, Rootman DS, Hunter W, et al: Malignant acanthosis nigricans. A case report. Ophthalmology 1993;100:1590-1592.

$\checkmark 8$ Lam S, Stone MS, Goeken JA, et al: Paraneoplastic pemphigus, cicatricial conjunctivitis, and acanthosis nigricans with pachydermatoglyphy in a patient with bronchogenic squamous cell carcinoma. Ophthalmology 1992;99:108-113.
9 Buttoni U, Dianzani C, Pranteda G, et al: Florid cutaneous and mucosal papillomatosis with acanthosis nigricans revealing a primary lung cancer. J Eur Acad Dermatol Venereol 2000; 14:205-208.

10 Gross G, Pfister H, Hellenthal B, et al: Acanthosis nigricans maligna: clinical and virological investigations. Dermatologica 1984; 168:265-272.

11 Andreev VC: Malignant acanthosis nigricans. Semin Dermatol 1984;3:265-272.

12 Brown J, Winkelmann RK: Acanthosis nigricans: a study of 90 cases. Medicine 1968; 47:33-51.

13 Clarke J: Malignant acanthosis nigricans. Clin Exp Dermatol 1977;2:167-170.

14 Schwartz RA, Burgess GH: Florid cutaneous papillomatosis. Arch Dermatol 1978;114 1803-1806.

15 Breathnach SM, Wells GC: Acanthosis palmaris: tripe palms. A distinctive pattern of palmar keratoderma frequently associated with internal malignancy. Clin Exp Dermatol 1980;5:181-189.

16 Cohen PR, Grossman ME, Silvers DN, et al: Tripe palms and cancer. Clin Dermatol 1993 11:165-173.

17 Verbov JL: Dermatoglyphics of malignant acanthosis nigricans. Clin Exp Dermatol 2005;30:302-303.

-18 Razack EM, Premalatha S, Rao NR, et al: Acanthosis palmaris in a patient with bullous pemphigoid. J Am Acad Dermatol 1987;16: 217-219.
19 Cruz PD, Hud JA: Excess insulin binding to insulin-like growth factor receptors: proposed mechanism for acanthosis nigricans. J Invest Dermatol 1992;98:82-85.

-20 Bonnekoh B, Thiele B, Merk H, et al: Systemic photochemotherapy (PUVA) in acanthosis nigricans maligna: regression of keratosis, hyperpigmentation and pruritus. Z Hautkr 1989;64:1059-1062.

21 Hazen PG, Carney JF, Walker AE, et al: Acanthosis nigricans presenting as hyperkeratosis of the palms and soles. J Am Acad Dermatol 1979;1:541-544.

22 Skiljevic DS, Nikolic MM, Jakovljevic A, et al: Generalized acanthosis nigricans in early childhood. Pediatr Dermatol 2001;18:213216.

23 Gorisek B, Krajnc I, Rems D, et al: Malignant acanthosis nigricans and tripe palms in a patient with endometrial adenocarcinoma - a case report and review of literature. Gynecol Oncol 1997;65:539-542.

$>24$ Holdiness MR: On the classification of the sign of Leser-Trélat. J Am Acad Dermatol 1988;19:754-757.

25 Brown J, Winkelmann RK: Acanthosis nigricans: a study of 90 cases. Medicine 1968; 47:33-51. 